\title{
MORPHOMETRIC EVALUATION OF NB84, SYNAPTOPHYSIN AND AGNOR IS USEFUL FOR THE HISTOLOGICAL DIAGNOSIS AND PROGNOSIS IN PERIPHERAL NEUROBLASTIC TUMORS (PNTS)
}

\author{
Aparecida de Cássia Carvalho ${ }^{1}$, Edwin Roger Parra ${ }^{1}$, Maria Cláudia Zerbini ${ }^{2}$,
} Venâncio Avancini Ferreira Alves ${ }^{3}$, Vera Luiza Capelozzi ${ }^{1}$, Leila Antonangelo ${ }^{1}$

Carvalho AC, Parra ER, Zerbini MC, Alves VAF, Capelozzi VL, Antonangelo L. Morphometric evaluation of NB84, synaptophysin and AgNOR is useful for the histological diagnosis and prognosis in peripheral neuroblastic tumors (pNTs). Clinics. 2007;62(6):731-40.

OBJECTIVE: To study the importance of NB84, synaptophysin and AgNOR and explore the quantitative association of these factors with diagnosis and outcome as well as the association between NB84 and AgNOR and other tumor and stromal factors in twenty-eight peripheral neuroblastic tumors.

METHODS: We assessed AgNORs, NB84, synaptophysin and several other markers in tumor tissues from 28 patients with primary neuroblastic tumors. The treatment included: surgery for stage 1, chemotherapy and bone marrow transplantation for most of stages 3 and 4. Histochemistry, immunohistochemistry and morphometry were used to evaluate the amount of tumor staining for AgNOR, NB84 and synaptophysin; the outcome for our study was survival time until death due to recurrent neuroblastic tumors.

RESULTS: Only stage $(\mathrm{p}<0.01), \operatorname{AgNOR}(\mathrm{p}<0.01), \mathrm{NB} 84(\mathrm{p}<0.01)$ and synaptophysin $(\mathrm{p}=0.01)$ reached statistical significance as prognostic indicators.

CONCLUSIONS: Determination of NB84 and synaptophysin are useful tools for the diagnosis of peripheral neuroblastic tumors The association of the evaluation of AgNOR expression by the tumor cells may provide an important contribution to the prognostic evaluation and management approach of the patients.

KEYWORDS: Neuroblastoma. AgNOR. DNA ploidy. NB84. Synaptophysin

\section{INTRODUCTION}

Peripheral neuroblastic tumors (pNTs) are a heterogeneous group of tumors that do not have a simple and reproducible morphological diagnosis and of which prognosis is variable, mainly due to the following features: a) pNTs

1. Department of Pathology, School of Medicine, University of São Paulo, São Paulo, Brazil.

2. Pediatric Institute of Clinical Hospital, School of Medicine, University of São Paulo, São Paulo, Brazil.

3. Department of Pathology of Institute Adolfo Lutz, São Paulo, São Paulo, Brazil.

E-mail: vcapelozzi@lim05.fm.usp.br

Received for publication on July 11, 2007

Accepted for publication on September 09, 2007 can arise in the adrenal medulla, sympathetic ganglia, and sympathetic paraganglia; b) these tumors exhibit complex histological findings; c) they do not have uniform terminology and criteria for the designation of types and subtypes and d) they are often diagnosed on the basis of a biopsy sample from the primary tumor or from a metastatic site, in which only a small portion of the tumor is available for the histological examination. Furthermore, to explain the biological relevance of the morphologic classification, pathologists now have to associate prognostic markers to the histological examination to better identify patients that will be assigned to different therapeutic protocols. Classical prognostic indicators such as age,,$^{1,-4}$ histological category or the International Neuroblastoma 
Pathology Committee ${ }^{5,6}$ Prognostic Group (INPC) are usually applied to large series of patients. Additionally, the criteria proposed by the INPC ${ }^{5,6}$ are only applicable when the entire or at least the major portion of the primary tumor is excised. However, sometimes the pNTs have already metastasized at the clinical presentation or the tumor cannot be surgically excised. In these cases, one may decide to perform only a biopsy from the primary tumor or from the metastasis (lymph node, liver, skin, bone marrow, or rarely, other sites) to attain the diagnosis. If the biopsy specimen is inadequate for the classification of the tumor type or subtype, tumor markers must be associated to the histological evaluation. At the histological examination, pNTs basically consist of small round cells, scattered around the loose stroma, the neuropil. The small round cell component frequently requires a differential diagnosis with lymphoma, Ewing's sarcoma and embryonal rhabdomyosarcoma, among others. Therefore, there is great interest in finding ways to identify which tumors are likely to recur and shorten survival, mainly in small series of patients.

In this regard, many authors have studied biological and diagnostic markers in tumors to discover which of these markers might be related to tumor diagnosis, recurrence and shortened survival. Because the monoclonal antibody NB84 directed to an unknown molecule of $57 \mathrm{kDa}$ can provide considerable assistance in the recognition of the neuroblastic differentiation, NB84 has been thought to be important as an adjuvant to the diagnosis in the routinely processed specimens. ${ }^{7-9}$ In addition, as the nuclear and stromal activity of tumor cells have been shown to influence tumor invasion and metastases, specific markers such as AgNOR, ${ }^{10-12}$ DNA ploidy, ${ }^{13-15} \mathrm{Ki}-67,{ }^{16,17}$ p53, ${ }^{15,16,18}$ collagen and neuropil matrix components have also been targeted as potential useful tumor markers. ${ }^{16,19-22}$

To validate the importance of NB84, synaptophysin and $\mathrm{AgNOR}$ and to explore the quantitative relationship between these factors and histological diagnosis and prognosis, as well as the relationship between NB84, synaptophysin and AgNOR and other tumor and stromal factors, we studied these markers in peripheral neuroblastic tumors and herein report our results.

\section{MATERIAL AND METHODS}

\section{Peripheral Neuroblastic Tumors (pNTs)}

Out of 300 NTs diagnosed from 1992 to 2002, a total of 28 cases from the Surgical Pathology Archives were included in this study (Table 1). The inclusion criteria comprised the following conditions: 1) specimen obtained by biopsy or surgical resection from the primary tumor; 2) no chemotherapy or radiotherapy treatment prior to the diagnosis; 3) sufficient amount of tissue in the paraffin blocks to perform serial sections for histochemical and immunohistochemical preparations and more than 10 mediumpower (100.) fields of adequate tissue for microscopic evaluation; and 4) medical records with adequate information. Small incisional biopsies from the primary or a metastatic site, possibly not representative of the tumor, were excluded from the study. Clinical staging was performed according to the revised International Neuroblastoma Staging System (INSS) criteria. ${ }^{23,24}$ Treatment included surgery for stage 1 (except for patient 13, who also received chemotherapy), chemotherapy and bone marrow transplantation for most of stages 3,4; patient $4 \mathrm{~S}$ received chemotherapy as well as undergoing surgery. All cases were reviewed and the classification according to the INPC system was applied. ${ }^{5,6}$ The following histological categories were defined: a) undifferentiated neuroblastoma (Figure 1A), undifferentiated pleomorphic neuroblastoma, poorly differentiated neuroblastoma (Figure 1B) and differentiated neuroblastoma (Figure $1 \mathrm{C})$; b) atypical nodular ganglioneuroblastoma, intermixed ganglioneuroblastoma (Figure 1D) and classical nodular ganglioneuroblastoma and c) maturing ganglioneuroma and mature ganglioneuroma. The histopathological classification and the staging data are shown in Table 1. The clinical records were reviewed for data concerning the relapse-free intervals and overall survival (Table 1).

\section{Morphological Study}

\section{Immunohistochemistry}

After surgical resection or biopsy, the tissue was formalin-fixed in 10\% neutral-buffered formalin and processed for routine histological analysis. The expression of p53, Ki67 , NB84 and synaptophysin was evaluated by immunohistochemistry, using the avidin-biotin immunoperoxidase technique. The antibodies used were: NCL-NB84 monoclonal mouse (clone NB84a; dilution of 1:400; Novocastra Laboratories - Newcastle, UK); monoclonal mouse antihuman directed to $\mathrm{p} 53$ protein (dilution of 1:100; Dako A/S, Glostrup-Denmark); monoclonal antibody directed to Ki-67 antigen (MIB-1; dilution of 1:100; Immunotech, Marseille - France) and monoclonal antibody to synaptophysin (363 M; dilution of 1:400; BioGenex, CAUSA). Brownish nuclear, membrane or cytoplasmic staining was considered to be evidence of the antigen expression by the cells, according to Ki-67 (Figure 1E, 1F), p53 (Figure 1G), NB84 (Figure 1H) and synaptophysin expression (Figure 1I), respectively. The positive index for each antibody was systematically determined in the "hot spot" areas. ${ }^{25}$ The counting of positive cells was performed for 
Ki-67, p53 and NB84 at a magnification of X1000 in noncoincident microscopic fields, counting a total of 1,000 tumor cells. The results were expressed as the index of positive cells. Synaptophysin was quantified in an image analyzer system. The positive areas occupied by this structure within a known tumor area were expressed in square micrometers $\left(\mathrm{mm}^{2}\right)$.

AgNOR. Slides for AgNOR evaluation were stained with the modified one-step silver colloid method ${ }^{26}$ in 3-mm thick sections. A total of 100 cells per case were analyzed at a 1000x magnification and the results were expressed in terms of mean area $\left(\mathrm{mm}^{2}\right)$ occupied by the dark dots inside the nucleus of the tumor cells (Figure 1J).

Extracellular Matrix. Collagen fibers were stained with a $0.2 \%$ Sirius red solution (Direct Red 80, CI 35780, Aldrich, Milwaukee, WI) dissolved in aqueous saturated picric acid solution. This staining method has been used since 1964 for collagen staining in histological specimens. The enhancement of collagen birefringence promoted by the picrosirius polarization method is specific for collagen- ous structures consisting of aggregates of orientated molecules. ${ }^{27-29}$ Five different fields were randomly selected and the density of collagen fibers was quantified at a magnification of x200, using an image analysis system (software Bioscan-Optimas 5.1, Bioscan Inc; Edmonds, Wash). The threshold for collagen was selected for individual cases, after enhancing the contrast up to a point at which the fibers were easily identified. The amount of collagen fibers was expressed in square micrometers (Figure 1K, 1L).

DNA. Tissue sections were treated with $5 \mathrm{~N}$ hydrochloric acid for $60 \mathrm{~min}$ at room temperature and then stained with the DNA Feulgen staining (Tripath Imaging Inc, Feulgen Biological Stain Kit, Auto Cyte - TI, Inc Burlington, NC, USA), Slides containing pellets of diploid and tetraploid hepatocytes (Cell Analysis Systems) were used as controls. Following dehydration with ethyl alcohol and clearing in xylene, the slides were coverslipped with Entellan $\left(\right.$ MERCK $\left.^{\circledR}\right)$. The evaluation of the nuclear DNA was performed in a digital image analyzer, using the CAS - "Quantitative DNA analysis" software (version 3.0). Control cells with a known DNA content (tetraploid rat hepatocytes)

Table 1 - Clinicopathologic data

\begin{tabular}{|c|c|c|c|c|c|c|c|c|c|c|c|c|c|}
\hline Case & Age (mo) & Stage & Recur & Death & $\begin{array}{l}\text { Overall } \\
\text { Surv } \\
\text { (mo) }\end{array}$ & $\begin{array}{l}\text { Histol. } \\
\text { Categ. }\end{array}$ & $\begin{array}{c}\text { INPC } \\
\text { PG }\end{array}$ & $\begin{array}{c}\mathrm{AgNOR} \\
\left(\mathrm{mm}^{2}\right)\end{array}$ & $\begin{array}{c}\mathrm{Ki}-67 \mathrm{n} / \\
1000\end{array}$ & $\begin{array}{c}\mathrm{p} 53 \mathrm{n} / \\
1000\end{array}$ & $\begin{array}{c}\text { NB84 n/ } \\
1000\end{array}$ & $\begin{array}{l}\text { Synapt } \\
\left(\mathrm{mm}^{2}\right)\end{array}$ & $\begin{array}{l}\text { Collagen } \\
\left(\mathrm{mm}^{2}\right)\end{array}$ \\
\hline 1 & 52 & 1 & No & No & 108 & 2 & $\mathrm{FH}$ & 6.87 & 7 & 0 & 180 & 39815.29 & 9536.90 \\
\hline 2 & 20 & 1 & No & No & 104 & 1 & UH & 5.68 & 130 & 0 & 35 & 765.75 & 1788.97 \\
\hline 3 & 50 & 4 & Yes & No & 97 & 1 & UH & 6.71 & 0 & 0 & 3 & 404.13 & 5692.26 \\
\hline 4 & 48 & 4 & NR & Yes & 11 & 1 & $\mathrm{UH}$ & 6.53 & 23 & 0 & 0 & 2095.73 & 707.90 \\
\hline 5 & 73 & 4 & NR & Yes & 16 & 1 & UH & 5.67 & 122 & 0 & 383 & 6070.45 & 3600.20 \\
\hline 6 & 32 & 1 & No & No & 74 & 1 & $\mathrm{FH}$ & 10.53 & 103 & 0 & 272 & 12943.75 & 4960.87 \\
\hline 7 & 8 & 3 & No & No & 58 & 1 & $\mathrm{UH}$ & 5.22 & 403 & 0 & 0 & 2050.51 & 4667.15 \\
\hline 8 & 12 & 4 & No & Yes & 16 & 1 & $\mathrm{FH}$ & 6.05 & 127 & 0 & 0 & 839.21 & 16225.63 \\
\hline 9 & 5 & $4 \mathrm{~S}$ & No & No & 52 & 1 & $\mathrm{FH}$ & 4.66 & 35 & 0 & 268 & 1056.62 & 4443.08 \\
\hline 10 & 1 & 3 & No & No & 49 & 1 & $\mathrm{FH}$ & 9.60 & 353 & 10 & 420 & 9024.27 & 24462.83 \\
\hline 11 & 16 & 1 & No & No & 47 & 1 & UH & 4.41 & 211 & 0 & 220 & 7815.42 & 5911.57 \\
\hline 12 & 51 & 3 & Yes & No & 50 & 1 & UC & 4.79 & 28 & 0 & 18 & 386.07 & 12161.41 \\
\hline 13 & 9 & 1 & Yes & No & 39 & 1 & $\mathrm{FH}$ & 5.03 & 210 & 0 & 603 & 208.99 & 9290.43 \\
\hline 14 & 11 & 3 & No & No & 37 & 1 & $\mathrm{FH}$ & 5.57 & 260 & 1 & 313 & 736.82 & 3054.31 \\
\hline 15 & 41 & 4 & Yes & Yes & 29 & 1 & $\mathrm{UC}$ & 7.68 & 5 & 0 & 468 & 16654.60 & 20694.24 \\
\hline 16 & 48 & 4 & NR & Yes & 10 & 1 & UH & 4.91 & 40 & 0 & 9 & 11377.19 & 17582.63 \\
\hline 17 & 72 & 4 & Yes & No & 33 & 1 & UC & 2.78 & 255 & 0 & 229 & 605.37 & 35526.60 \\
\hline 18 & 4 & 4 & Yes & No & 29 & 1 & UH & - & 254 & 6 & 205 & 2124.92 & 4947.70 \\
\hline 19 & 60 & 4 & Yes & No & 44 & 2 & $\mathrm{FH}$ & 3.97 & 4 & 28 & 165 & 18863.18 & 100449.88 \\
\hline 20 & 78 & 4 & NR & Yes & 14 & 1 & UH & 4.23 & 225 & 0 & 147 & 2063.27 & 47493.83 \\
\hline 21 & 13 & 1 & No & No & 23 & 1 & $\mathrm{FH}$ & 4.32 & 339 & 0 & 0 & 31.23 & 13733.51 \\
\hline 22 & 8 & 1 & No & No & 20 & 1 & $\mathrm{FH}$ & 4.30 & 347 & 2 & 324 & 4881.43 & 27382.86 \\
\hline 23 & 15 & 3 & Yes & No & 16 & 1 & $\mathrm{FH}$ & 5.03 & 214 & 3 & 313 & 15482.28 & 11403.13 \\
\hline 24 & 14 & 1 & No & No & 13 & 1 & $\mathrm{FH}$ & 5.25 & 73 & 4 & 386 & 848.45 & 2989.12 \\
\hline 25 & 29 & 3 & No & No & 118 & 1 & $\mathrm{UH}$ & 4.39 & 297 & 0 & 369 & 2981.25 & 5321.41 \\
\hline 26 & 14 & 3 & Yes & Yes & 92 & 2 & $\mathrm{FH}$ & 5.03 & 248 & 0 & 492 & 6841.63 & 37157.51 \\
\hline 27 & 69 & 4 & No & No & 87 & 1 & UH & 3.49 & 89 & 0 & 0 & 1940.79 & 10429.07 \\
\hline 28 & 36 & 1 & No & No & 80 & 2 & $\mathrm{FH}$ & 6.81 & 5 & 0 & 9 & 26602.42 & 20966.24 \\
\hline
\end{tabular}

Abbreviations: Recur (recurrence, 1 yes, 2 no), death (1 yes, 2 no), surv (survival); NR=never remitted; Histol. Categ.= histological categories: $1=$ neuroblastoma and 2=ganglioneuroblastoma. INPC PG = International Neuroblastoma Pathology Classification Prognostic Groups: FH = Favorable histology; $\mathrm{UH}=$ Unfavorable histology and $\mathrm{UC}=$ Unclassifiable; mo = months; synapt = synaptophysin 

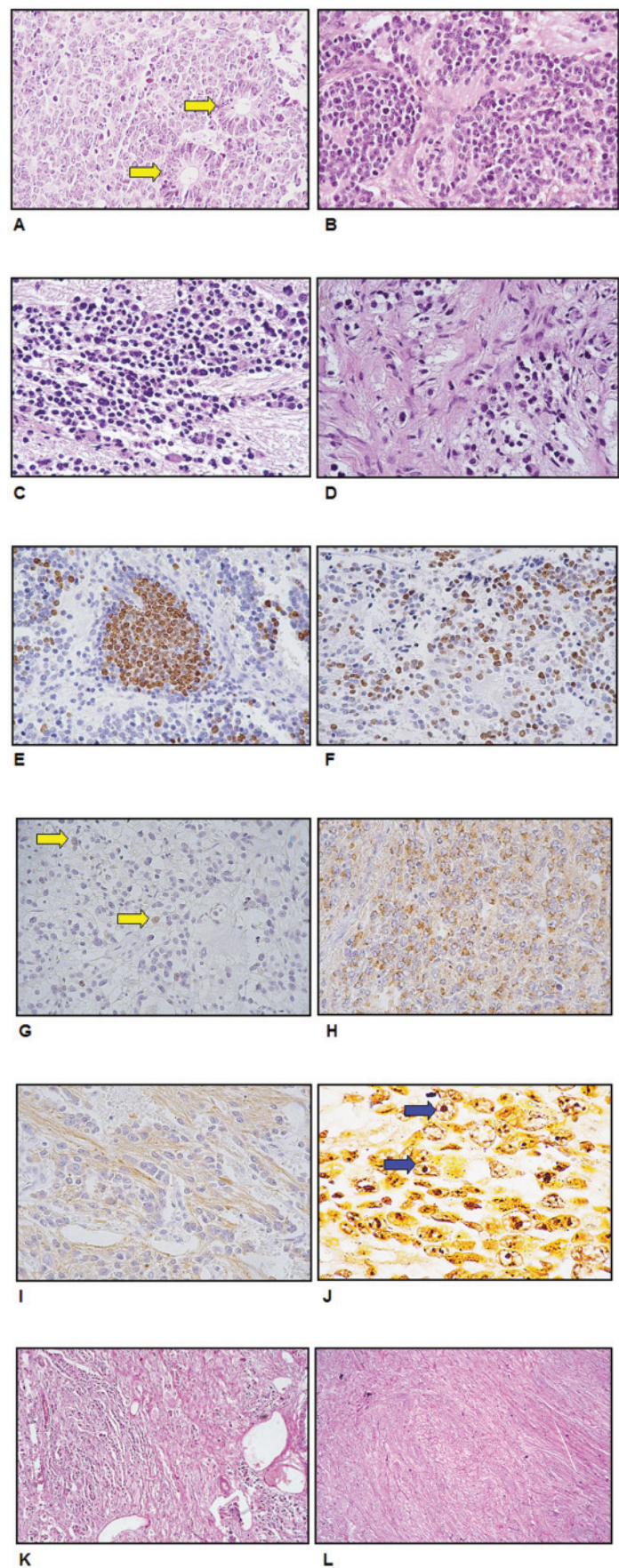

Figure 1 (Panels A to L). (A) Undifferentiating neuroblastoma: note hormerwright rosettes (arrows; H\&E X400); (B) Poorly differentiated neuroblastoma (H\&E X400); (C) Differentiating neuroblastoma (H\&E X400); (D) Intermixed ganglioneuroblastoma (H\&E, X400); (E) "Hot spot" in a case of poorly differentiated neuroblastoma, immunostained for Ki-67/MIB-1 (immunohistochemistry X400); (F) Ki-67/MIB-1 expression (stained brown) in a case of undifferentiated neuroblastoma (immunohistochemistry X400); (G) P53 expression (arrows) in a case of undifferentiated neuroblastoma (immunohistochemistry X400); (H) NB84 expression (stained brown) in a case of poorly differentiated neuroblastoma (oimmunohistochemistry X400); (I) Synaptophysin expression in a case of differentiated neuroblastoma: note synaptophysin-positive Schwann cells (stained brown) in the stromal septa, demarcating neuroblastic lobules (immunohistochemistry X400); (J) Undifferentiated neuroblastoma stained for "dots" of AgNOR (arrows); (K, L) Differentiated neuroblastoma stained for Picro-sirius (X400). were analyzed to determine the optical density of each slide, allowing the system calibration (external control). DNA from endothelial cells present in all specimens was measured separately and was used as the internal control. The DNA content of 200 tumor cells from every slide was analyzed. A frequency histogram using cell count $v s$. DNA content was generated. The results were expressed as DNA index (ID), and the tumor cells were classified as: diploid (ID: $0.8-1.2$ ); tetraploid (ID: $1.8-2.2$ ) and aneuploid for the other indexes. ${ }^{16}$

\section{Statistical Analysis}

The association between age, tumor stage, histological categories, INPC Prognostic Group, AgNOR, Ki-67, p53, NB84, DNA, collagen and synaptophysin was verified in subgroups of patients stratified by tumor recurrence using Fisher's exact test. For this analysis, AgNOR, Ki-67, p53, NB84, collagen and synaptophysin were dichotomized at the median. When applying the INPC pattern for age distribution, three groups were obtained: $<18$ months, 18 to 60 and $>60$ months. Survival was illustrated by KaplanMeier curves. Cox regression analysis was used to examine the relationship between pathological variables and mortality, controlling for other potential confounders including patients' age, stage, histological categories and INPC Prognostic Group. The impact of AgNOR was verified regarding survival time and recurrence, added as covariable dichotomized at the median (low and high) and as a continuous covariable. All statistical analyses were performed using the SPSS software program (SPSS Inc., Chicago, IL, version 9.0). The statistical significance was set at $p<0.05$.

\section{RESULTS}

The patients' ages at diagnosis ranged from 1 to 78 months (Table 1); thirteen (13) patients presented age $<18$ months (46.4\%), $11(39.2 \%)$ patients presented age from 18 to 60 months and $4(14.2 \%)$ patients presented age $>$ 60 months. No statistical difference was found between age and tumor recurrence $(\mathrm{p}=0.2)$ (Table 2; Figure 2A). For clinical stage 9 patients were at stage I; 7 patients at stage 3 ; 11 patients at stage 4 and only one patient at stage $4 \mathrm{~S}$ (Table 1). Of the patients at stages 1, 3 and $4 \mathrm{~S}$ disease (17 pts, $7 \%$ ) only 4 patients (14.3\%) presented disease recurrence. However, of the 11 patients $(39.2 \%)$ at advanced stage (4), 9 (32.1\%) presented recurrence, which showed statistical significance $(\mathrm{p}=0.01)$ when compared to the stage 1, 3 and $4 \mathrm{~S}$ patients. Histological categories included 24 cases of neuroblastomas and 4 cases of ganglioneuroblastomas. INPC Prognostic Groups included 14 cases of 
favorable histology, 11 cases of unfavorable histology and 3 cases were unclassifiable (Table 1). In this study, histological categories and INPC prognostic groups classification did no present statistical association with tumor recurrence. Eleven cases $(40.7 \%)$ presented high expression of AgNOR (5.0 mm2) associated to tumor recurrence, whereas 12 cases $(44.4 \%)$ presented low expression of this marker $\left(0.6 \mathrm{~mm}^{2}\right)$ without tumor recurrence, with a statistically significant difference $(\mathrm{p}<0.01$; Table 2, Figure 2B). Equally significant was the higher expression of NB84 (217/1000) in $12(42.9 \%)$ cases with disease recurrence compared to low expression $(20 / 1000)$ in $13(46.4 \%)$ cases without recurrence $(\mathrm{p}<0.01$; Table 2, Figure 2C). A significant dif- ference $(p=0.008)$ was found between the low amount $\left(505.6 \mathrm{~mm}^{2}\right)$ of synaptophysin found in 10 cases $(35.7 \%)$ with tumor recurrence and the high expression (7591.8 $\mathrm{mm}^{2}$ of this neuroendocrine marker detected in 11 cases $(39.3 \%)$ without tumor recurrence (Table 2, Figure 2D). Difference between the high amount of collagen (16904.1 $\mathrm{mm}^{2}$ ) found in $9(32.1 \%)$ cases with tumor recurrence and the low amount $\left(3227.2 \mathrm{~mm}^{2}\right)$ present in $10(35.7 \%)$ cases without tumor recurrence attained marginal significance $(\mathrm{p}=0.06$, Table 2). No statistical difference was found for the low and high expressions of Ki67, p53, DNA Ploidy and presence or absence of tumor recurrence.

Table 2 - Differences in the frequency of clinical and of morphological variables (threshold: low and high) in subgroups of patients stratified by tumour recurrence.

\begin{tabular}{|c|c|c|c|}
\hline \multirow[t]{2}{*}{ Variables } & \multicolumn{2}{|c|}{ Tumour Recurrence } & \multirow[b]{2}{*}{$p$ value } \\
\hline & Positive & Negative & \\
\hline \multicolumn{4}{|l|}{ Age (months) } \\
\hline $0 \mathrm{a}<18$ & $4(14.3 \%)$ & $9(32.1 \%)$ & \\
\hline 18 a 60 & $6(21.4 \%)$ & $5(17.9 \%)$ & 0.2 \\
\hline$>60$ & $3(10.7 \%)$ & $1(3.6 \%)$ & \\
\hline \multicolumn{4}{|l|}{ Stage } \\
\hline 1 & $1(3.6 \%)$ & $8(28.6 \%)$ & \\
\hline 3 & $3(10.7 \%)$ & $4(14.3 \%)$ & \\
\hline 4 & $9(32.1 \%)$ & $2(7.1 \%)$ & 0.01 \\
\hline $4 \mathrm{~S}$ & 0 & $1(3.6 \%)$ & \\
\hline \multicolumn{4}{|l|}{ Histologic Category } \\
\hline neuroblastoma & $11(39.3 \%)$ & $13(46.4 \%)$ & 0.8 \\
\hline ganglioneuroblastoma & $2(7.1 \%)$ & $2(7.1 \%)$ & \\
\hline \multicolumn{4}{|l|}{ INPC Prognostic Groups } \\
\hline Favorable Histology & $4(16 \%)$ & $10(40 \%)$ & 0.1 \\
\hline Unfavorable Histology & $6(24 \%)$ & $5(20 \%)$ & \\
\hline \multicolumn{4}{|l|}{ AgNOR } \\
\hline $0.6 \mathrm{~mm}^{2}$ & $1(3.7 \%)$ & $12(44.4 \%)$ & 0.0001 \\
\hline $5.0 \mathrm{~mm}^{2}$ & $11(40.7 \%)$ & $3(11.1 \%)$ & \\
\hline \multicolumn{4}{|l|}{ Ki67 } \\
\hline $34.8 / 1000$ & $6(21.4 \%)$ & $8(28.6 \%)$ & 0.7 \\
\hline $236.5 / 1000$ & $7(25.0 \%)$ & $7(25.0 \%)$ & \\
\hline \multicolumn{4}{|l|}{ p53 } \\
\hline $0 / 1000$ & $10(35.7 \%)$ & $11(39.3 \%)$ & 0.8 \\
\hline 4/ 1000 & $3(10.7 \%)$ & $4(14.3 \%)$ & \\
\hline \multicolumn{4}{|l|}{ NB84 } \\
\hline $20 / 1000$ & $1(3.6 \%)$ & $13(46.4 \%)$ & 0.0001 \\
\hline $217 / 1000$ & $12(42.9 \%)$ & $2(7.1 \%)$ & \\
\hline \multicolumn{4}{|l|}{ DNA Ploidy } \\
\hline tetraploid & $1(3.6 \%)$ & $5(17.9 \%)$ & \\
\hline diploid & $1(3.6 \%)$ & $1(3.6 \%)$ & 0.2 \\
\hline aneuploid & $11(40.7 \%)$ & $10(32.1 \%)$ & \\
\hline \multicolumn{4}{|l|}{ Synaptophysin } \\
\hline $505.6 \mathrm{~mm}^{2}$ & $10(35.7 \%)$ & $4(14.3 \%)$ & 0.008 \\
\hline $7591.8 \mathrm{~mm}^{2}$ & $3(10.7 \%)$ & $11(39.3 \%)$ & \\
\hline \multicolumn{4}{|l|}{ Collagen } \\
\hline $3227.2 \mathrm{~mm}^{2}$ & $4(14.3 \%)$ & $10(35.7 \%)$ & 0.06 \\
\hline $16904.1 \mathrm{~mm}^{2}$ & $9(32.1 \%)$ & $5(17.9 \%)$ & \\
\hline
\end{tabular}

Abbreviations: INPC - International Neuroblastoma Pathology Classification 


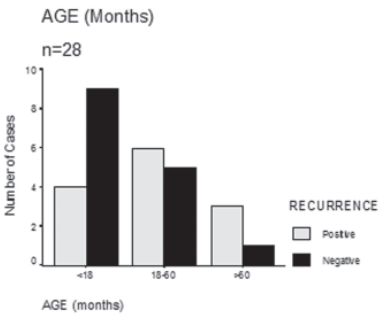

A

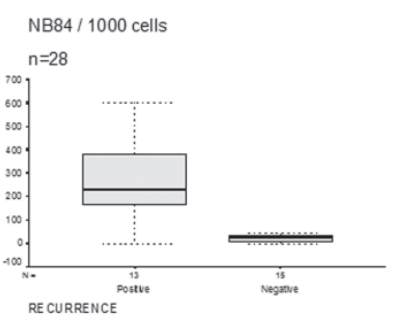

C

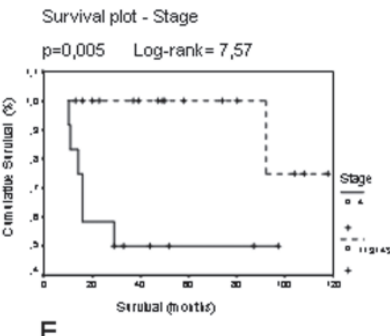

E

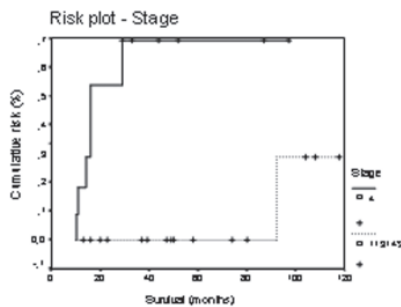

G

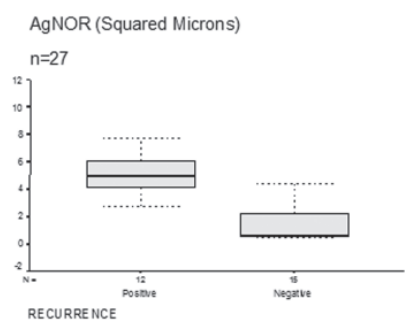

B
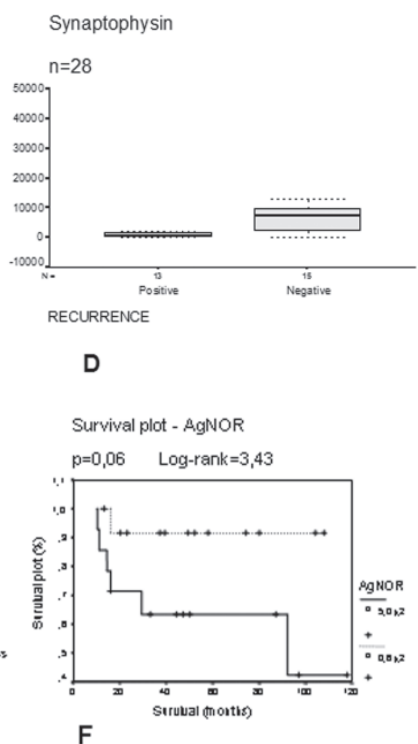

F

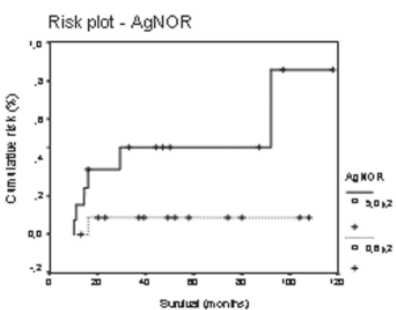

$\mathrm{H}$
Figure 2 (Panels A to $\mathbf{H}$ ) - Graphics illustrating differences in the frequency of clinical and morphological variables in subgroups of patients stratified by tumour recurrence (Panels A to D). In panel E is shown the survival plot by stage in patients with NTs. In panel F is shown the survival plot by positivity for $\mathrm{AgNORs}$ (high and low valours). In panels $\mathrm{G}$ and $\mathrm{H}$ the risk plot by stage and positivity for AgNORs, respectively).

\section{Survival Time Analysis}

The preliminary examination of the Kaplan-Meier survival curves (data not shown) demonstrated that, in this study, only patients with pathological stages 3 and 4 had different hazards for survival, with a median time of 92 and 29 months for each group, respectively (Figure 2E). The results of the Cox model are shown in Table 3. Two vari- ables were significantly associated with survival time: pathological stage and AgNOR expression. We observed that stage was significantly related to survival time and recurrence, even when the AgNOR expression was not considered ( $p=0.004$ and 0.003 , respectively). However, when AgNOR was added as a covariable, its association with survival and tumor recurrence was much stronger. The overall likelihood ratio (survival $v s$ recurrence) using only tumor stage was 29.71 and 60.0, respectively. When the AgNOR expression was associated (cutoff of $5.0 \mathrm{~m}^{2}$ ) to the stage, the likelihood ratio for survival and recurrence changed to 38.13 and 65.9, respectively. We also observe that the prognostic information provided by the AgNOR estimation was maximized when this parameter was used as a continuous variable, that is, without using a cutoff level (41.65 and 65.58 , respectively). The association between survival time and AgNOR expression is illustrated by the plots in Figure 2. The group with AgNOR $\leq 5 \mathrm{~mm}^{2}$ appears in the upper curve. Their median survival time was not reached during the follow-up period of observation, but it was quite long, at 100.33 months. On the other hand, the cases that presented AgNOR $>5 \mathrm{~mm}^{2}$ (lower curve) had a median survival time of only 92 months ( $\mathrm{p}=0.05$ by log rank test). Figures $2 \mathrm{G}$ and $2 \mathrm{H}$ we present the cumulative hazard curves for recurrence, according to stage (log rank test 11.8; $\mathrm{p}=$ 0.008 ) and $\mathrm{AgNOR}$ as a continuous variable (log rank test $67.2 ; \mathrm{p}<0.001)$.

Table 3 - Cox Proportional Hazard Model Analysis of Survival Timei ando Recurrence

\begin{tabular}{lcccc}
\hline Variable & Coefficient & SE & Likelihood ratio & P value \\
\hline Stage & $-2.47-11.59$ & $1.08-0.60$ & $29.71-60.0$ & $0.004-0.003$ \\
AgNOR & $1.07-2.38$ & $1.08-1.04$ & $38.13-65.9$ & $0.07-0.004$ \\
Stage AgNOR & $-2.26--0.94$ & $1.15-0.63$ & 32.48 & 0.008 \\
& $0.76-1.94$ & $1.14-1.08$ & 53.60 & 0.003 \\
AgNOR & & & $41.65-65.58$ & $0.00001-$ \\
& & & & 0.00001 \\
\hline
\end{tabular}

\section{DISCUSSION}

The majority of the small blue round-cell tumors can be diagnosed by the conventional histological analysis. However, diagnostic difficulties are often observed with the less differentiated ones, which show no neural, rhabdoid or epithelial differentiation at light microscopy. Immunohistochemistry has proved to be a useful adjunctive method for the differential diagnosis of these tumors. ${ }^{7,8,23}$ This is particularly true for the identification of lymphomas and leukemia, which are the most frequent members of this group of tumors. However, the diagnosis of neuroblastomas is more complex. There are only a few available monoclonal 
antibodies with reactivity against these tumors cells and these antibodies present variable and limited specificity and sensitivity for the routinely processed material. ${ }^{8}$

In this study, we tested the monoclonal antibody NB84, which showed immunoreactivity in approximately $90 \%$ of the tumors. Similar results were obtained by Thomas and coleagues $^{8}$, who observed reliable staining of $17 / 19(90 \%)$ neuroblastomas, which was negative for all other tumors except for Ewing's sarcomas, of which 9/14 (64\%) showed mainly focal positivity. This finding suggests that NB84 provides considerable assistance in the recognition of neuroblastomas and thus it is important to allow the most appropriate therapy to be established. Furthermore, we found a higher number of NB84 positive cells in the group of patients that presented tumor recurrence, the majority of them undifferentiated or poorly differentiated neuroblastomas, once more showing that NB84 can be used to predict the behavior of these tumors. Compared to NB84, we found that synaptophysin, a neuroendocrine marker of well differentiated cells, was positive in $100 \%$ of the cases and highly expressed by tumors without potential for recurrence, making synaptophysin a potential marker to predict tumor behavior. Similar findings were also observed by Miettinen ${ }^{7}$ and Bozzi. ${ }^{30}$

For clinical and pathological use, it would be desirable that the aforementioned adjuvant methods could also provide information related to tumor prognosis, in addition to being easy to perform as well as rapidly assessable and reproducible. ${ }^{9}$ Considering the large variety of tumors and the diversity of their biological behaviors, there is no universal marker that fulfills all these conditions. A variety of new markers has been proposed to aid in the diagnosis of some tumor types and to better evaluate the prognosis of these tumors. Recently, the quantitation of interphasic NORs has been associated with growth rate in neuroblastoma cell lines. ${ }^{11}$ A decreasing number of nucleolar organizer regions was found to be associated with histopathological grades, high nerve growth factor receptor (TRKA) expression and a better survival. ${ }^{12}$ Addditionally, stage IVS patients, lymph nodes and distant metastasis exhibited reduced nucleolar organizing region counts when compared with stage IV. ${ }^{10}$ Therefore, for all these reasons, we should not be surprised at the fact that that staining for AgNOR provides important prognostic information about pNTs and our results have now confirmed the prognostic importance of AgNOR in pNTs. Whereas only three prior studies were able to show a significant association between staining for AgNOR in the tumor and survival ${ }^{10-12}$ our results suggest that staining for AgNOR, used as a continuous variable, provides more prognostic information than the routine pathological staging. Although we were unable to identify a binary cutpoint in AgNOR, a natural dividing point was the median of 5.0 $\mathrm{mm}^{2}$ of nucleoli area expressing AgNOR and this point provided a practical means to separate them into two groups: patients with an expected short survival versus patients with an expected longer survival. Thus, staining of the pNTs for AgNOR offers us the potential to offer the use of adjuvant chemotherapy in patients likely to recur after the surgical excision of pNTs. In summary, to reach this conclusion will require a larger study in a randomized and prospective trial and we also believe it is important to validate our quantitative assessment of AgNOR in additional pNTs.

Among the microenvironmental features, the extracellular matrix components (collagen density) seems to be an important prognostic parameter, mainly in some special cancer types ${ }^{16,19}$. Although several studies of extracellular matrix proliferation in cancer have been carried out ${ }^{20,21}$ the association of these parameters with nuclear changes and oncogenic characteristics in pNTs, as well as the impact of these factors on prognosis have not been previously considered. Although with marginal significance, our data showed that tumors with higher collagen density were at an upper risk for recurrence. The extracellular matrix is an important, although poorly understood, collagenous host response to tumor invasion ${ }^{22}$. Shimosato et a ${ }^{19}$ reported one of the first studies about the impact of the extracellular matrix proliferation on cancer prognosis. They showed that tumors with a rich extracellular matrix tend to present higher blood vessel invasion and a greater incidence of lymph node metastasis, carrying a poor prognosis when compared to cases with low or no extracellular matrix proliferation. Regardless of the mechanism, the quantification of collagen can also provide prognostic information in pNTs. Other classic markers investigated in our study were Ki-67, ${ }^{17}$ p5 $3^{15,18}$ and DNA ploidy, ${ }^{13,14,23}$ which did not show association with NTs prognosis.

Finally, we should explain the negative results of classical prognostic indicators such as age,,${ }^{1-4}$ histological category or INPC Prognostic Group ${ }^{5,6}$ in our series. Based on the literature and the recent published article by Sano and colleagues, ${ }^{31}$ the International neuroblastoma pathology classification adds independent prognostic information beyond the prognostic contribution of age. Age has been used as a prognostic factor for patients with peripheral neuroblastic tumors (pNTs). According to these authors, the analysis disclosed a cutoff of around 18 months for the optimal prognostic distinction. The International Neuroblastoma Pathology Classification (INPC) differentiates favorable from unfavorable histology based on the age-appropriate evaluation of histological indicators (grade of neuroblastic differentiation, mitosis-karyorrhexis index) in the categories of nodular neuroblastomas and ganglioneuroblastomas. Sano's study ${ }^{31}$ 
showed that age, which was tested by using 3 different cutoffs (12, 18 and 24 months), was prognostically significant. INPC remained prognostically significant regardless of the age group to which it was applied. Prognostic effects of age and histological indicators were independently significant, i.e., age had a prognostic capacity beyond that of histological indicators, and histological indicators had a prognostic capacity beyond that of age. Due to the fact that INPC incorporated the age factor $(18,60$ months) into the system, it was better than age alone for the prognostic differentiation of pNT patients. Based on the literature and the recent published article by Sano and colleagues, who studied a series of 911 patients, the INPC adds independent prognostic information beyond the prognostic contribution of age. The great series of patients studied by these authors allow to better understand the definite role of classical prognostic indicators such as age, histological category and INPC. Prognostic Group and probably explains our negative findings. ${ }^{31}$

Despite the limitations observed in a small series of patients, we concluded that the determination of NB84 and synaptophysin are useful tools for the histological diagnosis of pNTs. When these markers are associated with the evaluation of the AgNOR expression by the tumor cells, they provide an important contribution to the prognostic evaluation and management approach of patients with pNTs. Further studies with a larger number of cases should be developed to assess the real value of the associated quantitation of NB84 and synaptophysin to the AgNOR expression for better diagnosis and prognosis attainment in patients with peripheral neuroblastic tumors.

\section{ACKNOWLEDGEMENT}

We are grateful to Dr. Katia Ramos Moreira Leite for supplying three cases from Hospital Sírio Libanês files.

This study was supported by the following Brazilian agencies: the National Council for Scientific and Technological Development [CNPq300430/95-7]; the Foundation for the Support of Research of the State of São Paulo [FAPESP2000/14336-0].

\section{RESUMO}

Carvalho AC, Parra ER, Zerbini MC, Alves VAF, Capelozzi VL, Antonangelo L. A avaliação morfométrica de NB84, sinaptofisina e AgNOR é útil para o dignóstico histológico e prognóstico dos tumores neuroblásticos periféricos (pNTs). Clinics. 2007;62(6):731-40.

OBJETIVO: Estudar a importância dos marcadores NB84 e AgNOR e explorar as relações quantitativas entre esses marcadores com o diagnóstico e prognóstico assim como as relações entre NB84 e AgNOR e outros marcadores tumorais e estromais em 28 tumores neuroblásticos periféricos.

MÉTODOS. Examinamos AgNOR, NB84 e sinaptofisina e vários outros marcadores em tecidos tumorais de vinte $\mathrm{e}$ oito pacientes com tumors neuroblásticos primários. Tratamento dos pacientes incluiu: cirurgia para o estágio 1, quimioterapia e transplante de medula óssea para a maioria dos pacientes nos estágios 3 e 4 . Utilizamos 
histoquímica, imunohistoquímica e morfometria para avaliar a intensidade e extensão de expressão do AgNOR, NB84 e sinaptofisina, tendo o prognóstico dos pacientes incluído o tempo de sobrevida até a morte por recurrência dos tumores neuroblásticos.

RESULTADOS. Estadiamento ( $\mathrm{p}<0.01)$, AgNOR $(\mathrm{p}<0.01)$, NB84 $(\mathrm{p}<0.01)$ e sinaptofisina $(\mathrm{p}=0.01)$ foram marcadores independents de sobrevida.

CONCLUSÕES. A determinação dos marcadores NB84 e sinaptofisina mostrou-se como uma ferramenta útil no diagnóstico dos tumors neuroblásticos periféricos; a associação desses marcadores à expressão de AgNOR pelas células tumorais contribuiu à determinação do prognóstico e estabelecimento do protocolo terapêutico para os pacientes.

UNITERMOS: Neuroblastoma. Prognóstico. AgNOR. Ploidia de DNA. NB84. Sinaptofisina.

\section{REFERENCES}

1. Breslow N, MacCann B. Statistical stimation of prognosis for children with neuroblastoma. Cancer Res. 1971;31:2098-103

2. Coldman AJ, Fryer CJH, Elwood JM, Sonley MJ. Neuroblastoma:influence of age at diagnosis, stage, tumor site, and sex on progression. Cancer. 1980;46:1896-901.

3. Jereb B, Bretsky SS, Vogel R, Helson L. Age and prognosis in neuroblastoma:review of 112 patients younger than 2 years. Am J Paediatr Hematol Oncol, 1984;6:223-43.

4. Hedborg F, Bjelfman C, Sparén P, Sandman S. Biochemical evidence for a maturation in morphologically poorly differntiated neuroblastomas with a favourable outcome. Eur J Cancer. 1995;31A:435-43.

5. Joshi VV. Peripheral Neuroblastic Tumors:Pathologic Classification basead on Recommendations of International Neuroblastoma Pathology Committee (modification of Shimada Classification). Pediatr Dev Pathol. 2000;3:184-99.

6. Shimada K, Ambros IM, Dehner LP, Hata J, Joshi VV, Roald B. Terminology and Morphologic Criteria of Neuroblastic Tumors Recommendations by the International Neuroblastoma Pathology Committee. Cancer. 1999;86:349-63.
7. Miettinen M, Chatten J, Paetau A, Stevenson A. Monoclonal antibody NB84 in the differential diagnosis of neuroblastoma and other small round cell tumors. Am J Surg Pathol. 1998;23:327-32.

8. Thomas JO, Nijar J, Turley H, Micklem K, Gatter KC. NB84: a new monoclonal antibody for the recognition of neuroblastoma in routinely processed material. J Pathol. 1991;163:69-75.

9. Linden MD, Torres FX, Kubus J, Zarbo RJ. Clinical application of morphologic and immunocytochemical assessments of cell proliferation. Am J Clin Pathol. 1992;97:S4-13.

10. Shimotake T, Iwai N, Tokiwa K, Deguchi E, Sawada T, Fushiki S. Increases number of argyrophilic nucleolar organizer regions between primary and metastatic sites predict tumor progression in stage IV and IVS neuroblastoma. Cancer. 1994;73:3103-7.

11. Derenzini M, Pession A, Farabegoli F, Trere D, Badiali M, Dehan P. Relationship between interphasic Nucleolar Organizer Regions and growth rate in two neuroblastoma cell lines. Am J Pathol. 1989;134:925-32.

12. Leuschner I, Schmidt D, Schulz R, Harms D. Nerve growth factor receptor (NGFR) and ras p21 expression in neuroblastoma (NBL):correlation to NOR, grading, and prognosis. Klin Padiatr. 1991;203-332. 
13. Gansler T, Chatten J, Varello M, Bunin GR, Atkinson B. Flow citometry DNA analysis of neuroblastoma:correlation with histology and clinical outcome. Cancer. 1986;58:2453-8.

14. Huddart SN, Muir KR, Parkes SE, Mann JR, Stevens MC, Raafat F, et al. Retrospective study of prognostic value of DNA ploidy and proliferative activity in neuroblastoma. J Clin Pathol. 1993;46:1101-4.

15. Layfield LJ, Thompson JK, Dodge RK, Kerns BJ. Prognostic indicator for neuroblastoma:stage, grade, DNA ploidy, MIB-1 proliferation index, p53, HER-2/ne4u and EGFr - a survival study. J Surg Oncol. 1995;59:21-7.

16. Demarchi LMM, Reis MM, Palomino SA, Farhat C, Takagaki TY, Beyruti $\mathrm{R}$, et al. Prognostic values of stromal density and PCNA, Ki-67, and p53 proteins in patients with resected adenocarcinoma of the lung. Mod Pathol. 2000;13:511-20.

17. Gerdes J, Lemke H, Baisch H, Wacker HH, Schwab U, Stein H. Cell cycle analysis of a cell proliferation-associated human nuclear antigen defined by the monoclonal antibody Ki-67. J Immunol. 1984;133:17105 .

18. Kerns BJ, Jordan PA, Moore MB, Humphrey PA, Berchuck A, Kohler $\mathrm{MF}$, et al. P53 overexpression in formalin-fixed paraffin embedded tissue detected by immunohistochemistry. J Histochem Cytochem. 1992; 40:1047-51.

19. Shimosato Y, Suzuki A, Hashimoto T, Nishiwaki Y, Kodama T, Yoneyama $\mathrm{T}$, et al. Prognostic implications of fibrotic focus (scar) in small peripheral lung cancers. Am J Surg Pathol. 1980;4:365-73.

20. Ohori NP, Yousem SA, Griffin J, Stanis K, Stetler-Stevenson WG, Colby $\mathrm{TV}$, et al. Comparison of extracellular matrix antigens in subtypes of bronchioalveolar carcinoma and conventional pulmonary adenocarcinoma:an immunohistochemical study. Am J Surg Pathol. 1992; 16:675-86.

21. Watanabe N, Nakajima I, Abe S, Ogura S, Isobe H, Kawakami Y. Staining pattern of type IV collagen and prognosis in early stage adenocarcinoma of the lung. JClin Pathol. 1994;47:613-5.
22. Barsky SH, Huang SJ, Bhuta S. The extracellular matrix of pulmonary scar carcinomas is suggestive of a desmoplastic origin. Am J Pathol. 1986; $124: 412-19$

23. Brodeur GM, Castleberry RP. Neuroblastoma. In: Pizzo PA, Poplack D, editors. Principles and practice of pediatric oncology. Philadelphia: Lippincott-Raven; 1997. p.761-97.

24. Brodeur GM, Pritchard J, Berthold F, Carlsen NL, Castel V, Castelberry $\mathrm{RP}$, et al. Revisions in the international criteria for neuroblastoma diagnosis, staging, and response to treatment. J Clin Oncol. 1993;11:1466-77.

25. Hall PA, Going JJ. Predicting the future:a critical appraisal of cancer prognosis studies. Review. Histopathology. 1999;35:489-94.

26. Ploton D, Menager M, Jeannesson P, Himber G, Pigeon F, Adnet JJ. Improvement in the staining and in the visualization of argyrophilic proteins of nucleolar organizer regions at the optical level. Histochem J. 1986; 18:5-14

27. Lemos M, Pozzo RMK, Montes GS, Saldiva PHN. Organization of collagen and elastic fibres studied in stretch preparations of whole mounts of human visceral pleura. Anat Anz. 1997;179:447-52.

28. Montes GS, Junqueira LCU. Histochemical localization of collagen and of proteoglycans in tissues. In: Nimni ME, editor. Collagen. Boca Raton, FL: CRC Press; 1988. p. 41-4.

29. Montes GS. Structural biology of the fibres of the collagenous and elastic systems. Cell Biol Int. 1996;20:15-27.

30. Bozzi (Bozzi F, Gambirasio F, Luksch R, Collini P, Brando B, FossatiBellani F. Detecting CD56+/NB84+/CD45- immunophenotype in the bone marrow of patients with metastatic neuroblastoma using flow cytometry. Anticancer Res. 2006;26:3281-7

31. Sano H, Bonadio J, Gerbing RB, London WB, Matthay KK, Lukens JN, Shimada H. International neuroblastoma pathology classification adds independent prognostic information beyond the prognostic contribution of age. Eur J Cancer 2006;42:1113-1119. 